In the week before the UK general election, experts assess the health policies of the three main parties, with regard to choice, incentives (for doctors to provide better standards of care), access, equality, and the overall cost of each party's programme. (Full versions are available at bmj.com)

\title{
Avoiding the issues
}

By not addressing the monopolistic nature of the NHS, all three parties fail to raise the real issues, says David Green

Comparing manifestos tells us as much about what the three main parties don't say as what they do. All three main parties agree that the NHS should continue to be a public sector monopoly. But the NHS is only one way to achieve the ideal shared across Europe: that no one should be denied health care because they lack money. A strong case can be made that the social insurance schemes of Germany, France, and Switzerland have been more successful than the NHS system. The poorest people in those countries enjoy a higher standard of care than in the United Kingdom, not having to face rationing and restricted choice.

However, the differences in policy between the three parties are not trivial. All three parties accept that the private sector should supply services to the NHS. The Tories are the keenest and want private providers to have a "right to supply" as long as they match NHS prices and standards.

But the Labour party is not far behind, claiming that by the end of 2008 patients will be able to choose any hospital that can meet NHS conditions. Moreover, it promises to use the independent sector to "drive contestability" within the NHS.

Labour still can't quite bring itself to speak favourably of "competition," a once hated idea that was misleadingly contrasted with cooperation instead of its real opposite, monopoly. But competition and contestability are based on the same assumption: that rivalry aids innovation, encourages mutual learning from mistakes, and increases the chances that the interests of patients will be put first.

All three parties say that "choice" is a good thing. For Labour, "extending patient pow-

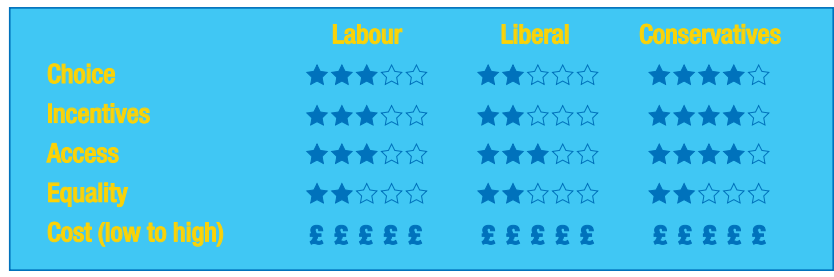

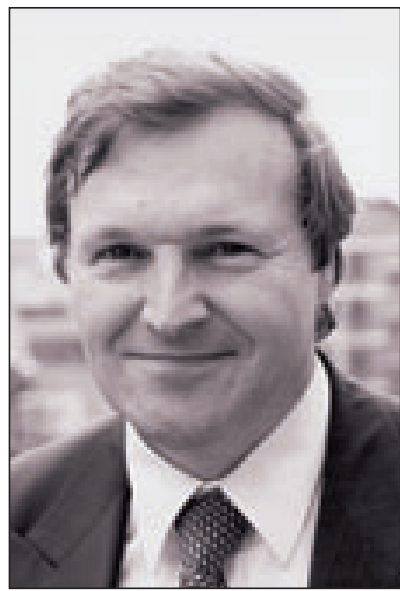

er and choice is crucial." The Liberals are more equivocal. They want to free doctors and nurses from central targets, on the assumption that this will "put patients first"-naively unaware that doctors sometimes put themselves first, as patients hoping to see their GP at short notice have discovered.

The Tories are the most committed to choice, but they have fallen into the same trap as Labour by using the language of consumerism as if it were consistent with public sector monopoly. In other walks of life-for instance, when we choose to spend more on food or housing-we do so in the light of the cost that we expect to bear personally. Choice within the NHS is treated like a one sided demand that our wants should be satisfied by somebody else.

Real choice can only be a real- ity where the self sufficient majority pay for their own health care through insurance while also subsidising people who are less well off. In countries with social insurance schemes the evidence is that about $30 \%$ of the population will need a subsidy from the other $70 \%$. But under such systems patients really are put first. The Liberals are claiming to be more honest than the other parties because they openly advocate an increase in the tax rate for the small number of people who earn more than $£ 100000$ a year, but taxing $1 \%$ of the population to pay for the health care of the other $99 \%$ is a populist ploy, not a moral principle.

Will doctors face incentives to provide higher standards of care? When it is fully under steam, Labour's system of payment by results will encourage better standards. The Tories' preference for all hospitals to be foundation hospitals will be more effective still; but the Liberals' plan to transfer the functions of primary care trusts to local councils will have the opposite effect.

What about equality? The term can mean different things, including the idea that no one should ever get more than anyone else, which explains the hostility of some MPs to foundation hospitals. If it refers to the absence of local variation, then the NHS has always failed to provide an equivalent service across the country.

David G Green director, Civitas: The

Institute for the Study of Civil Society

\section{Nowhere to go}

If you believe in a nationalised NHS, or if you
want to see health care privatised, Kieran
Walshe says you don't have anyone to vote for

So far in this election the debate on health policy has been reduced to a series of headline seeking but largely irrelevant issues, like methicillin resistant Staphylococcus aureus (MRSA) and hospital cleaning, matrons, health checks for immigrants, and new children's hospitals. These are manufactured disagreements that cover up the fact that the three main partiesand particularly Labour and the Conservatives-largely agree about the future direction of the NHS.
On money they all agree that the Labour government was right to commit itself to increase spending on the health service to European levels; they all support Labour's spending plans to 2008; and the only difference is that the Tories and the Liberal Democrats say they will spend even more. This government's lasting legacy will be that it had the courage to acknowledge that the NHS had been starved of resources and run on the cheap for much too long, and it embarked on an historic step change in NHS resourcing. In so doing, and in paying for it from general taxation, it torpedoed the longstanding argument from the right wing of the Tory party that the country could spend significantly more on health care only by moving to a system of social or private insurance to "top up" state funding.

On governance and structure, all three main parties agree that the NHS has been too centralised and that it makes no sense to try to manage the whole health service from Whitehall. Labour and the Tories want to create more (autonomous) 